Pacific Journal of Mathematics

CONTINUATION OF HOLOMORPHIC MAPPINGS, WITH 


\title{
CONTINUATION OF HOLOMORPHIC MAPPINGS, WITH VALUES IN A COMPLEX LIE GROUP
}

\author{
K. Adachi, M. Suzuki AND M. Yoshida
}

\begin{abstract}
In this paper it is shown that any holomorphic mapping of a domain $X$ over a Stein manifold in a complex Lie group $L$ can be continued to a holomorphic mapping of the envelope of holomorphy of $X$ in $L$.
\end{abstract}

1. Let $M$ be a complex manifold. A pair $(X, \psi)$ of a complex manifold $X$ and a locally biholomorphic mapping $\psi$ of $X$ in $M$ is called an open set over $M$. Moreover, if $X$ is connected, $(X, \psi)$ is called a domain over $M$. Let $(X, \psi)$ and $\left(X^{\prime}, \psi^{\prime}\right)$ be open sets over $M$. A holomorphic mapping $\lambda$ of $X$ in $X^{\prime}$ with $\psi=\psi^{\prime} \circ \lambda$ is called a mapping of $(X, \psi)$ in $\left(X^{\prime}, \psi^{\prime}\right)$. Consider domains $(X, \psi)$ and $\left(X^{\prime}, \psi^{\prime}\right)$ over $M$ with a mapping $\lambda$ of $(X, \psi)$ in $\left(X^{\prime}, \psi^{\prime}\right)$ such that each connected component of $X^{\prime}$ contains that of $\lambda(X)$. Let $Y$ be a complex manifold. Let $f$ be a holomorphic mapping of $X$ in $Y$. A holomorphic mapping $f^{\prime}$ of $X^{\prime}$ in $Y$ with $f=f^{\prime} \circ \lambda$ is called a holomorphic continuation of $f$ to $\left(\lambda, X^{\prime}, \psi^{\prime}\right)$. Let $\mathscr{F}$ be a family of holomorphic mappings of $X$ in $Y$. If any holomorphic mapping $f$ of $\mathscr{F}$ has a holomorphic continuation to $\left(\lambda, X^{\prime}, \psi^{\prime}\right),\left(\lambda, X^{\prime}, \psi^{\prime}\right)$ is called a holomorphic completion of $(X, \psi)$ with respect to the family $\mathscr{F}$. A holomorphic completion $\left(\tilde{\lambda}_{\mathscr{F}}, \widetilde{X}_{\mathscr{F}}, \tilde{\psi}_{\mathscr{F}}\right)$ of $(X, \psi)$ with respet to $\mathscr{F}$ is called an envelope of holomorphy of $(X, \psi)$ with respect to the family $\mathscr{F}$ if the following conditions are satisfied:

Let $\left(\lambda^{\prime}, X^{\prime}, \psi^{\prime}\right)$ be another holomorphic completion of $(X, \psi)$ with respect to $\mathscr{F}$. There is a mapping $\varphi$ of $\left(X^{\prime}, \psi^{\prime}\right)$ in $\left(\tilde{X}_{\mathscr{F}}, \widetilde{\psi}_{\mathscr{F}}\right)$ with $\tilde{\lambda}_{\mathscr{F}}=\varphi \circ \lambda^{\prime}$ such that $\left(\varphi, \tilde{X}_{\mathscr{T}}, \tilde{\psi}_{\mathscr{T}}\right)$ is a holomorphic completion of $\left(X^{\prime}, \psi^{\prime}\right)$ with respect to the family $\mathscr{F}^{\prime}$ of holomorphic continuations to $\left(\lambda^{\prime}, X^{\prime}, \psi^{\prime}\right)$ of all holomorphic mappings of $\mathscr{F}$.

If $\mathscr{F}$ is the family of all holomorphic functions in $X$, the envelope of holomorphy of $(X, \psi)$ with respect to $\mathscr{F}$ is called the envelope of holomorphy of $(X, \psi)$. If $\mathscr{F}$ consists of only one holomorphic mapping $f$ of $X$ in $Y$, the envelope of holomorphy of $(X, \psi)$ with respect to the family $\mathscr{F}$ is called the open set of holomorphy of $f$. Malgrange [5] proved the unique existence of an envelope of holomorphy, considering a connected component of the sheaf of all germs of families of holomorphic mappings with the same index set. By this construction of an envelope of holomorphy we have the following lemma. 
Lemma 1. Let $(X, \psi)$ be a domain over a complex manifold, $Y$ be a complex manifold and $\mathscr{F}$ be a family of holomorphic mappings of $X$ in $Y$. There is uniquely an envelope $\left(\tilde{\lambda}_{F}, \tilde{X}_{F}, \tilde{\psi}_{\mathscr{F}}\right)$ of holomorphy of $(X, \psi)$ with respect to $\mathscr{F}$. Moreover, let $\mathscr{G}$ be a subfamily of $\mathscr{F}$ and $\left(\tilde{\lambda}_{s}, \widetilde{X}_{s}, \tilde{\psi}_{s}\right)$ be the envelope of holomorphy of $(X, \psi)$ with

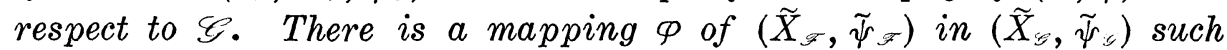
that $\left(\varphi, \widetilde{X}_{\bar{L}}, \tilde{\psi}_{\odot}\right)$ is the holomorphic completion of $\left(\widetilde{X}_{\mathscr{F}}, \tilde{\psi}_{\mathscr{F}}\right)$ with respect to $\mathscr{G}$.

\section{We put}

$$
\begin{aligned}
D= & \left\{z=\left(z_{1}, z_{2}, \cdots, z_{n}\right) \in C^{n} ;\left|z_{1}\right|<1+\varepsilon,\left|z_{j}\right|<1(j=2,3, \cdots, n)\right\} \\
& \cup\left\{z=\left(z_{1}, z_{2}, \cdots, z_{n}\right) \in C^{n} ; 1-\varepsilon<\left|z_{1}\right|<1+\varepsilon,\left|z_{j}\right|<1+\varepsilon\right. \\
& (j=2,3, \cdots, n)\}
\end{aligned}
$$

and

$$
E=\left\{z=\left(z_{1}, z_{2}, \cdots, z_{n}\right) \in C^{n} ;\left|z_{j}\right|<1+\varepsilon(j=1,2, \cdots, n)\right\}
$$

for a positive number $\varepsilon$ with $\varepsilon<1$. $E$ is the envelope of holomorphy of $D$.

Lemma 2. Let $L$ be a complex Lie group. For any holomorphic mapping $f$ of $D$ in $L$, there is a holomorphic mapping $g$ of $E$ in $L$ such that $g=f$ in $D$.

Proof. We may assume that $L$ is connected. Let $\mathscr{H}$ be the set of all holomorphic mappings of $D$ in $L$. We introduce in $\mathscr{H}$ the compact-open topology. As $D$ is analytically contractible to a point, $\mathscr{H}$ is a connected topological group. We put

$$
\begin{aligned}
K(\delta)= & \left\{z \in C^{n} ;\left|z_{1}\right| \leqq 1+\varepsilon-\delta,\left|z_{j}\right| \leqq 1-\delta(j=2,3, \cdots, n)\right\} \\
& \cup\left\{z \in C^{n} ; 1-\varepsilon+\delta \leqq\left|z_{1}\right| \leqq 1+\varepsilon-\delta,\left|z_{j}\right| \leqq 1+\varepsilon-\delta\right. \\
& (j=2,3, \cdots, n)\}
\end{aligned}
$$

and

$$
E(\delta)=\left\{z \in C^{n} ;\left|z_{j}\right|<1+\varepsilon-\delta(j=1,2, \cdots, n)\right\}
$$

for any positive number $\delta$ with $\delta<\varepsilon$. Let $m$ be the complex dimension of $L$ and exp be the exponential mapping of $C^{m}$ in $L$. exp maps an open neighborhood $U=\left\{w \in C^{m} ;\left|w_{j}\right|<a(j=1,2, \cdots, m)\right\}$ of the origin in $C^{m}$ biholomorphically on an open neighborhood $W$ of the unit element $e$ of $L$. Then $\log =(\exp \mid U)^{-1}$ is a biholomorphic mapping of $W$ onto $U$. We put $\mathscr{V}(1)=\{h \in \mathscr{C} ; h(K(\delta)) \subset W\}$. Then $\mathscr{C}(1)$ is a neighborhood of the unit element 1 of the topological 
group $\mathscr{H}$. Since $\mathscr{H}$ is connected, $\mathscr{H}$ is generated by $\mathscr{Y}(1)$. There is a finite number $s$ of elements $f_{1}, f_{2}, \cdots, f_{s-1}$ and $f_{s}$ of $\mathscr{Y}(1)$ such that $f=f_{1} f_{2} \cdots f_{s}$ in $D$. Each $\log f_{i}$ is a holomorphic mapping of $K(\delta)$ in the polydisc $U$. There is a holomorphic mapping $G_{i}$ of $E(\delta)$ in $U$ such that $G_{i}=\log f_{i}$ in $K(\delta) \cap E(\delta)$ for $j=1,2, \cdots, s$. We put $g=\exp G_{1} \exp G_{2} \cdots \exp G_{s}$ in $E(\delta)$. Then $g$ is a holomorphic mapping of $E(\delta)$ in $L$ such that $g=f$ in $K(\delta) \cap E(\delta)$. Since $\delta$ is arbitrary, we have Lemma 2 by the theorem of identity.

Let $(X, \psi)$ be a domain over a Stein manifold $S, L$ be a complex Lie group, $\mathscr{F}=\left\{f_{i} ; i \in I\right\}$ be a family of holomorphic mappings of $X$ in $L$ and $\left(\lambda, X^{\prime}, \psi^{\prime}\right)$ be the envelope of holomorphy of $(X, \psi)$ with respect to $\mathscr{F}$.

Lemma 3. $\left(X^{\prime}, \psi^{\prime}\right)$ is $p_{7}$-convex in the sense of Docquier-Grauert [2]:

Proof. Assume that $\left(X^{\prime}, \psi^{\prime}\right)$ were not $p_{7}$-convex. There is a continuous mapping $\varphi$ of the closure $\bar{D}$ of $D$, defined in (1) for a positive number $\varepsilon$ with $\varepsilon<1$, in $X^{\prime} \cup \tilde{\partial} X^{\prime}$ such that $\varphi(D) \subset X^{\prime}$, $\varphi(b, c) \in \tilde{\partial} X^{\prime}$ for $b \in C$ with $|b| \leqq 1-\varepsilon, c=\left(c_{2}, \cdots, c_{n}\right) \in C^{n-1}$ with $\left|c_{j}\right|=1(j=2,3, \cdots, n)$ and $\psi^{\prime} \circ \varnothing$ can be continued to a biholomorphic mapping $\pi$ of $E$, given in (2) for the above $\varepsilon$, in $S$. Here $\tilde{\partial} X^{\prime}$ is the boundary of the domain $\left(X^{\prime}, \psi^{\prime}\right)$ over $S$ defined in $\S 3.1 d$ of [2].

Let $f_{i}^{\prime}$ be a holomorphic continuation of $f_{i} \in \mathscr{F}$ to $\left(\lambda, X^{\prime}, \psi^{\prime}\right)$ for any $i \in I$. By Lemma 2 there is a holomorphic mapping $g_{i}$ of $E$ in $L$ such that $g_{i}=f_{i}^{\prime} \circ \varnothing$ in $D$ for any $i \in I$.

We consider the sum space $X^{\prime} \cup E$. Let $x_{1}$ and $x_{2}$ be, respectively, points of $X^{\prime}$ and $E$ such that $\psi^{\prime}\left(x_{1}\right)=\pi\left(x_{2}\right)$. Let $U_{1}$ and $U_{2}$ be, respectively, neighborhoods of $x_{1}$ and $x_{2}$ in $X^{\prime}$ and $E$ such that $\psi^{\prime} \mid U_{1}$ and $\pi \mid U_{2}$ are, respectively, biholomorphic mappings of $U_{1}$ and $U_{2}$ onto an open neighborhood $V$ in $S$. We shall identify $x_{1}$ and $x_{2}$ if and only if $f_{i}^{\prime} \circ\left(\psi^{\prime} \mid U_{1}\right)^{-1}=g_{i} \circ\left(\pi \mid U_{2}\right)^{-1}$ for any $i \in I$. Let $Z$ be the quotient space of $X^{\prime} \cup E$ by this equivalence relation. Let $\xi: X^{\prime} \rightarrow Z$ and $\eta: E \rightarrow Z$ be the canonical mappings. There is a locally topological mapping $\zeta$ of $Z$ in $S$ such that $\zeta \circ \xi=\psi^{\prime}$ and $\zeta \circ \eta=\pi$. Since $Z$ is a Hausdorff space, we can introduce in $Z$ a complex structure such that $(Z, \zeta)$ is a domain over $S$.

There is a holomorphic mapping $h_{i}$ of $Z$ in $L$ such that $h_{i} \circ \xi=f_{i}^{\prime}$ and $h_{i} \circ \eta=g_{i}$ for any $i \in I$. Then $h_{i}$ is a continuation of $f_{i}^{\prime}$ to $(\xi$, $Z, \zeta)$. Since $\left(\lambda, X^{\prime}, \psi^{\prime}\right)$ is the envelope of holomorphy of $X$ with respect to $\mathscr{F}$, there is a mapping $\mu$ of $(Z, \zeta)$ in $\left(X^{\prime}, \psi^{\prime}\right)$. Since $\zeta \circ \xi=\psi^{\prime}, \xi \circ \mu$ and $\mu \circ \xi$ are, respectively, the identities of $Z$ and $X^{\prime}$. Hence $\xi$ is a biholomorphic mapping of $X^{\prime}$ on $Z$. Since $(b, c) \in E$, we 
have $\varphi(b, c)=\left(\xi^{-1} \circ \eta\right)(b, c) \in X^{\prime}$. This is a contradiction.

3. Let $(X, \psi)$ be a domain over a Stein manifold $S,(\widetilde{\lambda}, \widetilde{X}, \widetilde{\psi})$ be its envelope of holomorphy, $L$ be a complex Lie group and $f$ be a holomorphic mapping of $X$ in $L$. Let $\left(\lambda, X^{\prime}, \psi^{\prime}\right)$ be the open set of holomorphy of $f$. By Lemma 3 and a theorem of Docquier-Grauert [2], $X^{\prime}$ is a Stein manifold. Hence $\left(X^{\prime}, \psi^{\prime}\right)$ is a domain of holomorphy of a holomorphic function in $X$. Since $(\widetilde{\lambda}, \widetilde{X}, \widetilde{\psi})$ is the envelope of holomorphy with respect to the family of all holomorphic functions in $X$, there is a mapping $\mu$ of $(\tilde{X}, \widetilde{\psi})$ in $\left(X^{\prime}, \psi^{\prime}\right)$ such that $\lambda=\mu \circ \tilde{\lambda}$ by Lemma 1. Let $f^{\prime}$ be the holomorphic continuation of $f$ to $\left(\lambda, X^{\prime}\right.$, $\left.\psi^{\prime}\right)$. Then $f^{\prime} \circ \mu$ is the holomorphic continuation of $f$ to $(\tilde{\lambda}, \widetilde{X}, \widetilde{\psi})$. Thus we have proved the following theorem.

THEOREM. Let $(X, \gamma)$ be a domain over a Stein manifold $S$ and $(\widetilde{\lambda}, \widetilde{X}, \widetilde{\psi})$ be its envelope of holomorphy. Any holomorphic mapping of $X$ in a complex Lie group $L$ has a holomorphic continuation to $(\widetilde{\lambda}, \widetilde{X}, \widetilde{\psi})$.

\section{REFERENCES}

1. H. Cartan und P. Thullen, Zur Theorie der Singularitäten der Funktionen mehrerer komplexer Veränderlichen, Regularitäts-und Konvergenzbereiche, Math. Ann., 106 (1932), 617-647.

2. F. Docquier und H. Grauert, Levisches Problem und Rungescher Satz für Teilgebiete Steinscher Mannigfaltigkeiten, Math. Ann., 140 (1960), 94-123.

3. J. Kajiwara, On the limit of a monotonous sequence of Cousin's domain, J. Math. Soc. Japan, 17 (1965), 36-46.

4. J. Kajiwara and E. Sakai, Generalization of Levi-Oka's theorem concerning meromorphic functions, Nagoya Math. J., 29 (1967), 75-84.

5. B. Malgrange, Lectures on the theory of functions of several complex variables, Tata. Inst. Bombay (1958).

Received March 6, 1972 and revised form May 25, 1972.

IBARAKI UNIVERSITY

TOYAMA UNIVERSITY

AND

FUKUOKa UNIVERSITY 


\section{PACIFIC JOURNAL OF MATHEMATICS}

\section{EDITORS}

D. Gilbarg and J. Milgram

Stanford University

Stanford, California 94305

R. A. Beaumont

University of Washington

Seattle, Washington 98105
J. DUGUNDJI* Department of Mathematics

University of Southern California Los Angeles, California 90007

RICHARD ARENS

University of California

Los Angeles, California 90024

\section{ASSOCIATE EDITORS}

E. F. BeCKenbach

B. H. NeUMaNN

F. WOLF

K. Yoshida

\section{SUPPORTING INSTITUTIONS}

UNIVERSITY OF BRITISH COLUMBIA

UNIVERSITY OF SOUTHERN CALIFORNIA

CALIFORNIA INSTITUTE OF TECHNOLOGY

UNIVERSITY OF CALIFORNIA

MONTANA STATE UNIVERSITY

STANFORD UNIVERSITY

UNIVERSITY OF TOKYO

UNIVERSITY OF NEVADA

UNIVERSITY OF UTAH

NEW MEXICO STATE UNIVERSITY

WASHINGTON STATE UNIVERSITY

OREGON STATE UNIVERSITY

UNIVERSITY OF OREGON

OSAKA UNIVERSITY

UNIVERSITY OF WASHINGTON

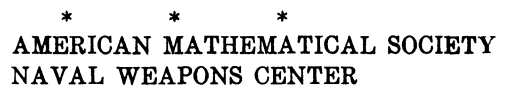

* C. DePrima will replace J. Dugundji until August 1974. 


\section{Pacific Journal of Mathematics}

\section{Vol. 47, No. $1 \quad$ January, 1973}

K. Adachi, Masuo Suzuki and M. Yoshida, Continuation of holomorphic

mappings, with values in a complex Lie group ....................

Michael Aschbacher, A characterization of the unitary and symplectic groups

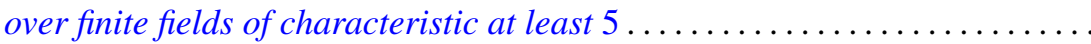

Larry Eugene Bobisud and James Calvert, Energy bounds and virial theorems for abstract wave equations....................................

Christer Borell, A note on an inequality for rearrangements ................

Peter Southcott Bullen and S. N. Mukhopadhyay, Peano derivatives and general

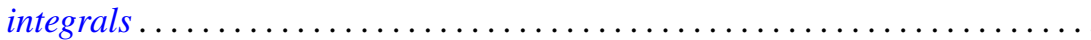

Wendell Dan Curtis, Yu-Lee Lee and Forrest Miller, A class of infinite dimensional subgroups of $\operatorname{Diff}^{r}(X)$ which are Banach Lie groups .........

Paul C. Eklof, The structure of ultraproducts of abelian groups ...............

William Alan Feldman, Axioms of countability and the algebra $C(X) \ldots \ldots \ldots$

Jack Tilden Goodykoontz, Jr., Aposyndetic properties of hyperspaces...........

George Grätzer and J. Płonka, On the number of polynomials of an idempotent algebra. II ...........................................

Alan Trinler Huckleberry, The weak envelope of holomorphy for algebras of

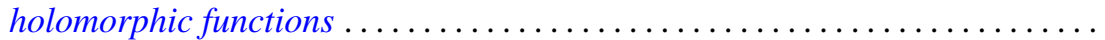

John Joseph Hutchinson and Julius Martin Zelmanowitz, Subdirect sum decompositions of endomorphism rings . . . . . . . . . . . . . . . .

Gary Douglas Jones, An asymptotic property of solutions of

$y^{\prime \prime \prime}+p y^{\prime}+q y=0$.

Howard E. Lacey, On the classification of Lindenstrauss spaces .

Charles Dwight Lahr, Approximate identities for convolution measure algebras.

George William Luna, Subdifferentials of convex functions on Banach

spaces.

Nelson Groh Markley, Locally circular minimal sets. .

Robert Wilmer Miller, Endomorphism rings of finitely generated projective modules

Donald Steven Passman, On the semisimplicity of group rings of linear

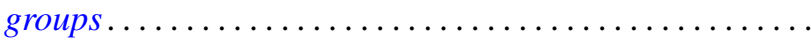

Bennie Jake Pearson, Dendritic compactifications of certain dendritic spaces.

Ryōtarō Satō, Abel-ergodic theorems for subsequences ...... .

Henry S. Sharp, Jr., Locally complete graphs. . .

Harris Samuel Shultz, A very weak topology for the Mikusinski field of

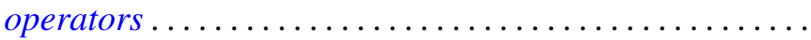

Elena Stroescu, Isometric dilations of contractions on Banach spaces ...

Charles W. Trigg, Versum sequences in the binary system ... . .

William L. Voxman, On the countable union of cellular decompositions of n-manifolds 